\title{
A PARIS DE NESTOR VITOR E O MUNDO DE PASCALE CASANOVA
}

\author{
César Braga-Pinto
}

Divididas entre o testemunho e a memória, as narrativas de viagem inevitavelmente oscilam, não somente entre diferentes geografias, mas também entre diferentes temporalidades, ora convergentes, ora conflitantes ${ }^{1}$. O livro Paris: impressões de um brasileiro, de Nestor Vitor (publ. 1911/1913), evidencia essa ambiguidade dos relatos de viagem em geral, e ainda apresenta outras, específicas de sua própria posição no espaço e no tempo. Por um lado, a viagem do brasileiro a Paris, no início do século XX, ainda em plena Belle Epoque, significa a busca de um encontro com a essência do contemporâneo, ou, utilizando-se já a imagem de Pascale Casanova, "o tempo do meridiano de Greenwich literário” (CASANOVA, 1999, p. 116). Por outro, o regresso ao Brasil faz do destino europeu um objeto não só de devoção, mas também de crítica, relativizando-se assim qualquer nostalgia e fazendo do reencontro com a origem pátria o signo menos de uma ausência do que de uma quasepromessa. Assim, esse livro (extraordinário) de Nestor Vitor se constrói não só como um relato essencialmente e assumidamente anacrônico, mas como a própria impossibilidade de uma visão sincrônica, ou melhor, de uma experiência verdadeiramente contemporânea do mundo: "Nós outros, os homens, ou ainda não representamos nosso tempo na altura necessária ou já somos um pouco a personificação do passado, incapazes de refletir a vida na sua incessante transformação" (VITOR, 1913, p. 394,

1 Para uma discussão do tempo nas narrativas de viagem, ver Korte (2008). 
itálicos nossos). Assim, a realidade presenciada em Paris e rememorada a partir do Rio de Janeiro faz o paranaense reconsiderar a temporalidade instável do dernier cri da moda que se revela como o sempre-já démodé, um sempre déjà- $v u$ da modernidade europeia.

Pode-se então dizer que estas memórias de viagem do escritor brasileiro se fazem em um processo autoconsciente de tradução e negociação transatlântica, onde se confundem o ensaio (auto)etnográfico e o espírito universalista. Por isso, não se deve confundir seu assumido cosmopolitismo com aquela "atração do mundo", ou aquela dupla ausência, a tal moléstia sentida e vivida por Joaquim Nabuco. A frase do famoso cap. IV de Minha Formação é bastante conhecida: "De um lado do mar sente-se a ausência do mundo. Do outro, a ausência do país. O sentimento em nós é brasileiro, a imaginação, europeia”. O que mais tarde o leva a reconsiderar: "Quando, porém, entre a pátria, que é o sentimento, e o mundo, que é o pensamento, vi que a imaginação podia quebrar a estreita forma em que estavam a cozer ao sol tropical os meus pequenos debuxos de almas, Usted me entienden, deixei ir a Europa, a história, a arte, guardando do que é universal só a religião e as letras" (NABUCO, 1900, pp. 11-12)2. Ao contrário de Nabuco, como procurarei mostrar, para Nestor Vitor, a ausência do mundo será percebida não só ali, em sua própria casa, mas também lá do outro lado do oceano, no suposto centro cosmopolita, na capital da República Mundial das Letras, a que ele mesmo chama de Cidade Única. Já a ausência do país se ressentirá pouco ou quase nada durante aqueles quatro anos na Europa, onde Nestor Vitor convive com seus conterrâneos e parece frequentar confortavelmente a sociedade francesa. Ou seja, Nestor Vitor não se vê obrigado a escolher entre a pátria e o mundo, ou entre o sentimento (íntimo) e o pensamento (público). Por outro lado, escrevendo a partir do Brasil, o retornado raramente lamentará sua condição de desterrado em sua própria terra. Sua retórica não será nunca a das raízes, poeta e crítico simbolista que era, e autor de títulos como Signos (1897) e Transfigurações (1902). Na verdade, sempre tivera muito pouca simpatia pelos nacionalismos do tipo dos Les Deracinés (1897) ou Os desplantados de um Maurice Barrès, com seu chamado romance da energia nacional, obra analisada por ele já no primeiro ensaio de seu primeiro livro de crítica, $A$ Hora, de $1901^{3}$. Se é que há nostalgia, tal nostagia seria a do Ser, em seu exílio mais existencial do que circunstancial.

2 Para uma leitura da dupla ausência de Nabuco ver, entre outros, Santiago (2004).

3 Para uma discussão da ambiguidade entre nacionalismo e cosmopolitismo em Nestor Vitor, ver Braga-Pinto (2012). 
Tendo vivido exatos 32 anos em cada século, Nestor Vítor dá-nos a impressão de estar sempre um pouco fora de seu próprio tempo. Em 1902, quatro anos depois da devastadora morte de seu venerado companheiro Cruz e Sousa, fixa-se na capital francesa, onde ficaria até 1905. Até então, havia publicado, além do volume de ensaios citado, um livro de contos [Signos (1897)]; uma monografia sobre Cruz e Sousa (1899); um romance, entitulado Amigos (1900); e uma coleção de poemas, com o título Transfigurações (1902); além de uma tradução de Maeterlinck, Sabedoria e Destino (1902). Ou seja, sua produção intelectual e literária ainda não estava clara, estando distribuída em diversos gêneros e interesses. As "Impressões de um brasileiro" que aqui nos interessam só seriam redigidas cerca de quatro anos depois de sua volta da Europa, em 1905, o que lhe permite um certo distanciamento da experiência vivida no estrangeiro, agora reconstituída a partir do $\mathrm{Brasil}^{4}$. O livro marca uma nova orientação crítica, voltada agora para obras e assuntos nacionais, dos quais tratará mais tarde em publicações tais como A Terra do Futuro - Impressões do Paraná (1913), Três Romancistas do Norte (1915), Farias Brito (1917), A crítica de Hontem (1919), Folhas que Ficam (1920), Cartas à gente nova (1924), Os de Hoje (publicado postumamente em 1938). Além desses, publicaria ainda O Elogio da Criança (1915) e O Elogio do Amigo (1921).

Na ocasião de seu lançamento, Paris (1911) recebeu os mais altos elogios de Silvio Romero, segundo o qual Nestor Vitor revelava-se, "no gênero, o mais notável de nossas letras" (ROMERO, 1949, p. 389). No entanto, quase toda a sua obra ficcional e poética permance até hoje praticamente esquecida5. Já sua vasta produção crítica é mais comumente lembrada como a do crítico oficial do simbolismo, responsável pela recuperação da obra de Cruz e Sousa, mas ainda permanece excluída do grupo de críticos contemporâneos formado pela tríade Romero, Veríssimo e Araripe. Dos poucos que mencionam Paris, praticamente todos lamentam seu esquecimento, como Brito Broca, para quem o livro é "qualquer coisa de novo e notável [...] uma interpretação da famosa cidade, ou melhor, uma explicação, feita por um crítico agudíssimo e inteligente. A chave de Paris, eis o que o escritor nos oferece, com a sua visão de psicólogo e sociólogo" (BROCA, 1993, p. 139); um "livro único em

4 De Paris, NV escrevia artigos para os jornais O País e Correio Paulistano, alguns dos quais se encontram republicados em Obra Crítica, v. 3, pp. 87-137. A segunda parte do livro de aforismos, Folhas que ficam, "a sabedoria do exílio", reflete os anos vividos em Paris.

5 Sobre Paris, ver Grossi (1993); Nitrini (1998) e Lins (2007). 
nossas letras, constituindo verdadeira exegese de uma cidade e de um povo" (BROCA, 2000, p. 150).

Considerando ele mesmo seu ponto de vista de escritor colonizado, a questão que Nestor Vitor se colocará desde o prefácio a seu relatomemória de viagem é a de como, por quê, ou ainda com que direito deveria o brasileiro fazer uma obra de observação e análise sobre o centro cosmopolita europeu; ou, em suas próprias palavras: “...escrever sobre mundos e civilizações superiores àquelas que provimos, em que nos desenvolvemos, de que, pois, necessariamente temos a marca" (VITOR, 1913, p. ii). Assim, a princípio a narrativa de viagens escrita a partir da periferia se encontraria em evidente desvantagem em relação a esse mundo já tão globalizado e, particularmente à França, com toda sua longa tradição no gênero e de seu incontestável prestígio. Para Nestor Vítor - ao contrário da solidão cultural em que se encontra o brasileiro em suas viagens pela Europa, vivida sempre como uma espécie de deficiência, e muitas vezes expressa em gestos compensatórios -, o viajante francês nunca terá que se preocupar em não parecer ridículo: mesmo o mais medíocre e superficial dos escritores franceses nunca está sozinho, pois sempre pode contar com o prestígio da civilização a que pertence e que o legitima. A desvantagem e o redobrado esforço exigido ao escritor periférico não deve no entanto levá-lo a evitar o desafio e a responsabilidade. Pois mesmo se, como afirma, "hoje o mundo vai-se tornando um pequeno globo", dispondo de poucas novidades a serem reveladas pelo escritor; mesmo se tudo já tivesse sido dito por melhores e mais reputados escritores sobre o centro do mundo, algo ainda haveria a ser dito pelo viajante periférico. $O$ interesse primeiro de seu relato estaria em melhor compreender o que há de europeu no meio americano (e não a sua ausência) - tanto as qualidades quanto os defeitos que ali se reproduzem; mas também em se representar o que raramente se reconhece como elemento essencial e formador da sociedade parisiente, ou seja, o próprio estrangeiro: "àqueles dos nossos que vão até lá, que lá se demoram, e até que lá deixam seus ossos num caso ou noutro, a mim, a ti, talvez, meu leitor, a outro brasileiro como nós, ao sul-americano em geral, e até por muitos lados ao próprio yankee, seja multimilionário ou pobretão" (VITOR, 1913, p. v). Ou seja, uma crônica dos exilados (sul-) americanos em Paris (conhecidos por lá como os rastaqueras) estaria (e talvez ainda hoje esteja) por ser feita.

Nestor Vítor nota que naquele momento, mais do que nunca a narrativa de viagens estava em grande voga na França, e explica assim a função que ela despempenharia por lá: 
[...] mostrar à França que o mundo se estende além de suas fronteiras, e que o fato de esquecê-lo é o propósito mais ininteligente, mais funesto em que ela poderia se assentar; dizer-lhe que a nossa era não é dos que se deixam ficar extáticos, na contemplação do próprio umbigo, mas antes dos povos modestos, entretanto ativos, curiosos, compreensivos, assimiladores, que se completam, ou pelo menos que se armam segundo é mister nesta civilização agonal e transitória. (VITOR, 1913, p. 415)

Assim, a literatura de viagens teria o propósito de estabelecer um diálogo e, por vezes, um embate com o outro. Esta relação e este interesse pelo outro é o que em outras ocasiões ele define como "simpatia", um conceito central em toda a sua crítica posterior. No entanto, mesmo que a França tenha já uma longa tradição no gênero, e que a narrativa de viagem francesa possa servir como uma referência nas impressões do brasileiro, de nada adiantaria simplesmente emulá-la. Ao contrário, é necessário primeiramente penetrar sua lógica e sua dinâmica, assim como suas possíveis limitações. Para melhor compreender e se inserir neste gênero consolidado e consagrado na França, Nestor Vitor faz um longo desvio, estabelecendo uma analogia entre os relatos de viagem e a instituição dos museus - de cuja ausência o Brasil também se ressente.

\section{O MUSEU E O MUNDO}

Segundo o escritor brasileiro, assim como grande parte dos relatos de viagens franceses, os museus teriam representado não verdadeiramente um interesse pelo outro, mas sim o modo específico pelo qual a França expressa e divulga o seu "bom gosto", justificando assim sua posição central no mundo. Por mais que ele admire a superioridade da civilização francesa, e o seu valor enquanto "espelho do mundo", logo de início Nestor Vítor questiona a legitimidade de tal posição, de certo modo adquirida pela violência colonial. Pois apesar de boa parte das obras de arte estrangeiras que se encontram expostas na França serem de fato aquisições legítimas, muitas delas seriam, ao contrário, "remanescentes das depredações feitas a outros povos", ou simplesmente adquiridas graças ao privilegiado poder econômico e político da metrópole. Tal assimetria é o que possibilitaria que os museus franceses, e sobretudo o Louvre, criassem a ilusão de que Paris era, não somente o centro, mas uma verdadeira miniatura do mundo, de tal modo que, ironicamente, para quem o visita, a viagem por outras regiões acabe por parecer, se não desnecessária, nada mais que "complementares daquilo que na sua feição mais importante e geral, ali tão cômoda e agradavelmente se 
nos patenteia" (VITOR, 1913, p. 137). Ou seja, assim como a narrativa de viagem, o museu também orderna e exibe o mundo todo de acordo com o gosto e a inteligibilidade francesa. Esta mistificação do outro, própria da atividade museográfica, aponta Nestor Vitor, por vezes confundese com a falsificação. E lembra, com uma dose de ironia, o escândalo arqueológico mais ou menos recente da "tiara de Saitafernas," uma peça falsa adquirida pelo Louvre como original, assunto que ainda agitava a imprensa francesa durante sua estadia em Paris: um dos casos mais famosos de fraude arqueológica, descobriu-se em 1903 que a tal coroa de ouro maciço, supostamente do século 3 a.C. e adquirida pelo Louvre por 200 mil francos em 1896, era na verdade obra de um artista russo contemporâneo (Israel Rouchomovski) .

Além disso, Nestor Vitor elabora uma distinção importante entre a necessidade de se preservar (uma obra da destruição) e o gesto a seus olhos um tanto suspeito de conservar, que é o que o museu francês se esforça em fazer, restaurando, polindo e dando um brilho homogêneo a toda uma coleção, bem "ao gosto pechoso e coquet", que no fundo representaria antes de tudo a essência do próprio francês. Assim, mesmo o modo de se organizar os objetos nos museus dependeria de certos artifícios, usados para se criar um maior efeito de autenticidade, "mas que por isso mesmo afrancesa inevitavelmente em grau considerável tudo o que eles queiram interpretar ou ainda simplesmente por em evidência, do estrangeiro" (VITOR, 1913, p 138). Ou seja, ao começar sua análise da instituição museológica a partir da maneira pela qual a França inventa aquilo que se entende por "o mundo," e questionando a autenticidade dos seus acervos e coleções, assim como a legitimidade de suas exibições, não é só o museu, mas também o próprio cosmopolitismo francês que no olhar do brasileiro vai adquirindo certos ares de farsa. Se o escritor periférico (destituído de museus ${ }^{7}$ ) não deixa de admirar esse formidável "talento de exibir" próprio dos franceses, também não lhe passa despercebido que o critério praticado está longe de ser puramente estético ou mesmo históriográfico, que no fundo a prática museológica reflete não só o "gosto" francês, mas frequentenemte suas preferências geográficas e notadamente políticas. Assim, o que a perspectiva do escritor paranaense faz é transformar a resignação do homem culturalmente subordinado em um poder de re-significação do centro, evidenciando a capacidade 
que a cultura francesa tem de iludir, principalmente a "nós outros, os profanos em arte", e de assim ocultar "grandes e deploráveis hiatos" (VITOR, 1913, p. 139). E conclui: "Em todo caso, o quadro é tão vasto, tão magnífico, tão imponente, que, se por um lado amenora, acaso, perante nosso espírito, a ideia do mundo que representa, por outro engrandece sobremodo aos nossos olhos o povo que teve a capacidade de organizálo" (VITOR, 1913, p. 140). Assim, Nestor Vitor nota que o museu, assim como todo o cosmopolitismo parisiense que o caracteriza, é concebido de modo a confirmar a incontestável superioridade da cultura francesa, "com prejuízo de todos os outros países, de cuja arte só possamos fazer ideia pelos elementos que se nos oferecem naqueles museus" (VITOR, 1913, p. 141).

Nestor Vitor propõe então que a experiência da visita ao museu francês seja vivida de forma critica e sempre metonimicamente, remetendo assim o visitante a outras culturas e geografias, mas nunca substituindo o valor de outras viagens e outros museus, localizados em outras nações (no caso, europeias), com seus diferentes critérios de seleção e exibição. Pois mesmo as obras francesas adquiririam novo colorido e significado quando desterritorializadas e vistas, por exemplo, no contexto de um museu inglês ou italiano. Assim, o deslocamento (no caso, ainda pela Europa) seria capaz não somente de proporcionar uma visão mais ampla e imparcial (ou talvez mais assumidamente parcial) do mundo como também de reduzir a máquina cosmopolita francesa à sua condição nacional e assim reintroduzir a perspectiva nacional na desordem das pluralidades do mundo. Um rigoroso critério de seleção pode ter lá seu valor, pondera o autor, como teriam valor um belo e bem escolhido buquê de flores, mas nem por isso ele deixa de se perguntar: "Que valem, porém, tais vantagens diante da grandeza, amplitude e naturalidade de todo um cerrado e cambiante vergel"? (VITOR, 1913, p. 142) É justamente tal parcialidade do processo seletivo (que se quer representativo) que o viajante brasileiro constata em sua visita à Bienal de Veneza (em 1905) quando tem a oportunidade de conhecer a verdadeira diversidade da arte europeia contemporânea, em salas inteiras dedicadas a países como a Hungria, que, por conta de proximidade com a Alemanha, é sistematicamente ignorada pelo establishment museológico francês. É também na Itália que se familiariza com artistas alemães.

É verdade que, enquanto o grande museu francês inventa muito rigidamente o patrimônio universal, o excesso desordernado de obras contemporâneas expostas em galerias menores e nos salões deslumbra e chega a oprimir o viajante brasileiro, em momentos que ele confessa 
um "quase desespero" (VITOR, 1913, p. 148). No entanto, mesmo esse deslumbramento com a modernidade logo se dilui, e o impacto do novo se transforma logo em déjà $v u$, em lugar comum, em mediocridade mesmo. No fundo, pouco vale procurar nos estrangeiros radicados em Paris a diversidade do mundo contemporâneo, já que esses se quase sempre se adaptam e se confundem ao gênio francês:

É preciso nunca ter vivido em França para ignorar de que limitada compreensibilidade e tolerância é o grosso público ali por tudo quanto se revele contrário à índole francesa [...] Afinal, o que geralmente se expõem em Paris, do estrangeiro, é o que ali já se começa, não só a compreender, porém, pelo menos em parte, a estimar, é o que vai conseguindo incorporar-se à cultura francesa. Assim, não se exagera muito dizendo que é o que já se vai tornando até certo ponto francês. (VITOR, 1913, p. 156)

Enfim, se a analogia inicial se mantém, o leitor deverá concluir que, como nos museus, as narrativas de viagem francesas mistificam e obscurecem o "mundo" diante de suas inclinações políticas e estéticas, além dos preconceitos e uma certa estreiteza de visão que lhes é muito própria. Seja nas ruas de Paris, seja nos grandes museus ou nos livros de viagens, os estrangeiros na capital servem nada mais do que para confirmar un certo gosto intransigente do francês. Na literatura, por exemplo, "a França continua a satisfazer-se a si mesma, interessada antes de tudo pelos seus próprios autores, pela sua própria vida emocional, que só estes poderão interpretar ao seu gosto" (VITOR, 1913, p. 403$)^{8}$. Finalmente, partindo de uma série de lugares comuns, tais como aqueles em que se proclama que a França "é a segunda pátria de todos os homens" ou que Paris é a cidade em que "todos se podem sentir como em sua casa” (VITOR, 1913, p. 422), Nestor Vitor não deixa de assinalar a xenofobia francesa e a dificuldade do estrangeiro em ali sobreviver.

"Em França o forasteiro ainda é encarado bastante pelo modo e ver antigo, de que resultou para os romanos o mesquinho aforismo do hospes hostis" exceto no que diz respeito aos interesses comerciais (p. 427) [...] "O meteco ou estrangeiro residente é de regra aos olhos do francês uma espécie de galinha de ovos de ouro" (p. 446) [...] Não se fala da extraordinária vantagem que há

8 Em Folhas que ficam, NV narra a seguinte anedota, sob o título "O francês em viagem":

Estamos em Itália:

- Que laranja doce! As que se comem em França pedem açúcar em geral.

- Ainda assim eu gosto mais das laranjas que se chupam lá. (VITOR, 1920, pp. 88-89) 
para a Cidade Luz em atrair todos os anos a massa enorme de visitantes atrai, da Europa como do mundo inteiro, gente que vem essencialmente para gastar, muitas vezes como nunca se tinham disposto a fazê-lo. (VITOR, 1913, p. 447)

\section{AS LETRAS E A REPÚBLICA DE PASCALE CASANOVA}

Esta crítica ao etnocentrismo parisience elaborada por Nestor Vitor nos princípios do século XX parece em quase tudo coincidir, e de certo modo estar contida, no retrato da República Mundial das Letras oferecido por Pascale Casanova, em sua análise do processo que ela mesmo define como Parisianização ou universalização através da negação da diferença (CASANOVA, 2002, p. 193). Mas talvez este seja justamente o maior o problema deste livro, em si mesmo tão abrangente e tão cosmopolita - obra que defende tanto a desuniversalização do mundo quanto a re-historicização das literaturas individuais; uma obra que muito provavelmente consideraria bem ao gosto francês, espécie de narrativa de viagem pelo mundo todo, obra povoada e protagonizada por um grupo seleto de ex-cêntricos, em uma perspectiva espacial e museológica onde nada parece ficar de fora. Cheio de promessas e boas intenções, o livro de Casanova se propõe a exibir as assimetrias na dinâmica da chamada república mundial das letras e a servir como "arma crítica a serviço de todos os excêntricos (periféricos, desprovidos e dominados) literários”, assim como instrumento para lutar contra "as evidências, as arrogâncias, as imposiçõs e as determinações da crítica central [da qual ela provavelmente se imagina excluída], e que tudo ignora da desigualdade de acesso ao universo literário" (CASANOVA, 2002, p. 424). No entanto, ao terminar de ler o livro, parece-me difícil não ficar justamente com a sensação contrária, ou seja, a de que sua análise contribui para reproduzir, mais do que desascelerar a máquina museográfica francesa, mesmo se, generosamente incorporando a periferia do mundo, exibindo-a com exemplos de obras muito bem escolhidas, muito polidas e bem conservadas, e supostamente reintegradas ao seu autêntico contexto histórico original, tudo muito bem organizado e iluminado.

Não é minha intenção dar conta de todas as nuances e ramificações do método e do (de certo modo admirável) panorama propostos por Casanova que, sem dúvida, tem pontos de grande interesse; nem mesmo apontar todas as suas contradições, que também não sou 
poucas9. Permito-me no entanto fazermos algumas observações. Primeiramente, eu não posso deixar de me perguntar o que significa hoje este súbito retorno ao literário e, particularmente na forma de uma nova história literária conciliado a um renovado estruturalismo, justamente quando os estudos culturais pareciam ter sucedido em expandir a noção de literatura e de texto, expansão que exigiria uma formação interdisciplinar do crítico, e que alguns de nossos colegas, verdadeiros especialistas, muitas vezes viram com desconfiança, e por vezes até mesmo como uma ameaça aos estudos literários. Mais curioso ainda é que, como sugeriu Prendergast, o conceito de literatura, ou de letras utilizado por Casanova, parece limitar-se às belles-lettres: literatura escrita, obra da imaginação, ficcional, moderna e cosmopolita (PRENDERGAST, 2004, p. 21). Não sei se caberia aí a filosofia, as ciências humanas, ou mesmo a crítica literária, já que se poderia argumentar que não é de hoje que a universidade norte-americana tem consagrado, ou pelo menos financiado os mais destacados representantes do uma suposta crítica mundial (sendo a própria Casanova professora visitante na universidade de Duke). As outras artes também se excluem, e se em algum momento o cinema entra nessa história, trata-se do cinema "de arte", talvez o mais "literário" dos cinemas, cujo prestígio é definido por festivais internacionais como o de Cannes, e não por Hollywood. Assim, o homem de letras ex-cêntrico é revalorizado (muitas vezes supervalorizado) pela crítica francesa, e o que veio a se chamar sujeito subalterno nos estudos pós-coloniais deixaria de ter relevância pelo fato de sobrepor o político ao literário. Ao separar literatura e sociedade, ou ao postular (a partir de Bourdieu) um campo literário mundial autônomo, ou relativamente autônomo que seja, a própria literatura parece se recuperar de seu suposto desprestígio e, há de se perguntar, se com ela também a capital mundial das letras, justamente quando Paris vai se tornando centro e símbolo de xenofobia, além de tensões sociais e étnicas. Por outro lado, ao se enfatizar mapas de circulação e, em certa medida, a dinâmica do mercado, este modelo de literatura mundial e este novo método propõe abandonar tudo o que se pareça com a "explicacion de texte", o close reading, a análise do texto propriamente dito (o modelo de Damrosh, diga-se de passagem, escapa a essa tendência, que me aparece mais acirrada e dogmática em Moretti com sua proposta de distant reading $)^{1 \mathrm{o}}$.

9 Para uma crítica mais detalhada da obra, ver Prendergast (2004).

1o Para um apanhado geral da teoria de Moretti, assim como do debate criado em torno dela, ver Serlen (2010). Em seu mais recente livro, Gayatri Spivak (2012) dedica três 
A outra, digamos, surpresa, é ver (ao contrário do que fora imaginado por Goethe) a categoria do nacional voltar com tal força e soberania, justo quando categorias transnacionais como gênero, raça, etnia, sexualidade e mesmo classe pareciam ter formado categorias mais do que estabelecidas na crítica cultural - pelo menos no que diz respeito à produção de língua inglesa. A história literária do "mundo", ou melhor, a história das relações inter-nacionais proposta por Casanova, parece ser uma linha evolutiva que finalmente e paradoxalmente culmina com a entrada das nações periféricas como novos protagonistas da modernidade europeia. A intenção declarada de Casanova (como a de Moretti) é, com efeito, de denunciar a desigualdade, a assimetria na estrutura formada pela circulação de livros e ideias, de formas e conteúdos literários, de prestígio e capital cultural, e a violência mesmo da disputa pelo controle do tempo literário de Greenwich, a partir do qual todos os outros relógios devem se acertar (essa imagem dos ponteiros a serem acertadas também está presente, diga-se de passagem, em vários momentos na obra de Nestor Vitor). Seu projeto consiste em temporalizar a literatura e logo espacializar o tempo (o que a princípio é também a função dos grandes museus), com o objetivo de denunciar, ou exibir em termos de espaços e distâncias, as desigualdades segundo a qual o etnocentrismo é repetidamente interpretado temporalmente como atraso ou anacronismo.

Assim, Casanova aponta aquilo que Nestor Vitor já percebia, ou seja, que desde o século XVI a França toma para si o privilégio de centro do mundo literário, projetando-se para o resto do mundo como definidora do bom-gosto, do novo, do universal, do clássico, tudo de forma desnacionizadamente universal. Este poder teria sido contestado, mas não destruído, nos séculos XVIII e XIX pelo novos nacionalismos, muitas vezes fundado em um novo interesse pela cultura popular; já o século XX (com os efeitos do imperialismo e da descolonização) vê a entrada em cena dos ex-cêntricosos assimilados como Naipaul (talvez ainda Nabuco?), que tentariam ser absorvidos pelo centro; ou os rebeldes, que procuram ora ignorar, ora diferenciar-se do centro em termos nacionais e literários, combatendo o espírito imitativo, e muitas vezes lançando mão do nacional-popular; e finalmente os revolucionários que, esses sim, teriam o poder de criar uma nova medida do tempo literário. Eles sim, teriam atingido a verdadeira "autonomia", para além do prestígio

capítulos ao debate em torno do conceito de literatura mundial, do qual ela tem sido uma incansável crítica. 
nacional (a falsa autonomia representada pela França) e da disputa internacional.

Muito do que há de confuso e problemático no decorrer dessa argumentação tem a ver com a o emprego de certos conceitos e metáforas (ainda de certa inspiração bourdieuana) - como por exemplo toda a retórica do capital, da disputa, da rivalidade, da competição, dos ganhadores e perdedores, do sucesso e do fracasso, em que os espaços nacionais são personificados, mas os agentes propriamente ditos nem sempre são identificados. Um conceito particularmente problemático nessa narrativa é o de "autonomia" - que parece ser, por um lado, puramente literário e, por outro, econômico e político, em que o que está em pauta é também, mas não somente a conquista de reconhecimento e prestígio. Assim, na narrativa de Casanova haveria de um lado uma falsa autonomia - a da França, ou de uma certa França usurpadora de talentos e fundos de reserva culturais; por outro, uma nova e legítima autonomia, ou seja, a diferenciação conquistada heroicamente por algumas nações periféricas, como no espaço literário nacional brasileiro pós-semana de 22; e finalmente a verdadeira e autêntica autonomia, a daqueles grandes artistas que criam a duras penas as condições de sua própria produção literária, independente do nacional, capazes enfim de desafiar e restabelecer as regras do próprio meridiano literário de Greenwich. Esses seriam uma parte de uma segunda geração do nacional-autônomo, os verdadeiros homens livres, genuinamente independentes e inovadores.

Igualmente problemáticas são as escolhas dos exemplos, inevitáveis, é claro, mas nem por isso menos significativas. Assim, o que impediria o reconhecimento de autores periféricos geniais como Machado de Assis, ou críticos brilhantes como Antonio Candido, é que ambos teriam sido "vitimas de um ostracismo estrutural" para o qual a marginalidade da lingua portuguesa teria contribuído, ou mesmo sido inteiramente responsável. Ironicamente, mais uma vez, é a representante crítica francesa que parece se atribuir o poder lisonjeiro de consagração do ex-cêntrico injustiçado. Assim, a autora também valorizará como momento fundamental da conquista da autonomia, aquele nacionalismo paradoxal de um "tupi tocando o alaúde" (imagem que outro francês, Serge Gruzinski, também não se cansará em citar) (GRUZINSKI, 2002, p. 7); Mário de Andrade seria assim um excêntrico rebelde, situado injustamente nas margens da república mundial das letras, mas cuja "autonomia" é agora reconhecida pelo lugar no museu reservado ao Brasil, organizado talvez menos na lógica do Louvre do que ao gosto de um Quai-Branly. Finalmente, a representante da crítica francesa, sem nenhuma hesitação, consagra Samuel Becket na posição de um, se não 
o mais autônomo de todos os escritores. Depois de quase 400 páginas de leitura, encontra-se mais uma vez a consagração da inovação (pós-) modernista.

Vale de todo modo reiterar certos pontos do argumento, dentre os quais aqueles que considero problemáticos e particularmente incômodos:

1. Sem chegar a ser surpreendente, não há como negar o fato incontestável de que pelo menos durante o século XX, autores e obras literárias se tornam consagradas enquanto universais a partir de Paris. Casanova sem dúvida mostra os vários mecanismos dessa consagração, que inclui a imprensa, as influências, os apadrinhamentos, as traduções, os prêmios etc. Como sabemos, uma versão desta lógica, no âmbito não da mundialização, mas da nacionalização da literatura, já havia sido desenvolvida por Sérgio Miceli em seu clássico "Intelectuais e Classe Dirigente no Brasil" (MICELI, 2001, pp. 69-281).

2. O modelo estrutural e cerrado proposto por vezes me dá a sensação de que não há como intervir no que é um fato consumado. Pois o descritivo muitas vezes parece um tanto prescritivo: Greenwich pode ser alterado por alguns, poucos, geralmente os excêntricos, sempre homens geniais, mas permanece um referencial único: o marco do novo e do moderno, o prêmio que todos querem conquistar no final da corrida. Assim, a guerra continuaria, sendo que a proposta declarada do livro é a de enviar armas (críticas) para os periféricos para que lutem "contra os que ignoram a desigualdades do acesso" [ao universo literário]. [Talvez seja o caso de reler a obra de um outro francês: Maurice Blanchot em um ensaio chamado "O Tempo das enciclopédias" (1957) via o esforço enciclopédico como algo do passado, e o desafio hoje seria o de de um novo discurso e de uma outra visão: a do fragmentário.] (BLANCHOT, 1957)

3. É bem verdade que tanto o modelo como os exemplos estudados nos oferecem elementos para novas interpretações da obra e da trajetória deste ou daquele autor (sempre os escolhidos). Mas não explicam tudo, nem todos. A batalha de Becket e o "caminho, histórico, de seu acesso à liberdade formal e estilística”, podem nos fornecer alguns elementos para melhor compreender sua trajetória, muito mais do que sua obra. $\mathrm{Ou}$ seja, pode explicar a gênese, mas não explica, digamos, o valor da obra, nem a razão pela qual foi consagrado pelos donos do capital cultural, consagração que é curiosamente reconfirmada pela própria Casanova.

4. A preferência pelo ex-cêntrico nos leva finalmente a considerar o seu oposto, o escritor que, como que nascido de família culturalmente abastada, e por conta de seu privilégio, acaba sendo marginalizado 
ou desconsiderado neste novo mapa da literatura mundial. De fato, o escritor francês e a capital literária mesmo permancem, senão ilegíveis, de pouco interesse [Flaubert, por exemplo, é citado apenas uma vez; Gide está praticamente ausente, a não ser como autoridade legitimadora e dotada de capital cultural]; mas como interpretar a pequena distância, ou mesmo a coincidência, desses personagens em relação ao centro? Será que esse critério poderia ser usado também para melhor situar o prestígio da obra da própria Pascale Casanova?

5. Note-se que a literatura brasileira aparece em três momentos: (a) com a ajuda de Antonio Candido, na análise da adopção tardia e permanência do naturalismo, muitas vezes entendida pela crítica eurocêntrica como anacronismo; (b) na análise do desprestígio literário da língua portuguesa, exemplicado pelos casos de "injustiça" contra Machado de Assis e o próprio Antonio Candido; (c) com a luta pela autonomia representada pelo nacionalismo rebelde (mas ainda não revolucionário) de Mário de Andrade que, segundo Casanova, se encontra exatamente na mesma posição de Du Bellay quando este reivindicava o fim da dependência do francês em relação ao Latim. O objetivo final de Mário seria assim o de recolher fontes (constituir um arquivo, ou melhor, um acervo) para melhor acumular capital literário e cultural. Por isso, Casanova o escolhe como sendo o mais representativo "emblema de todas as narrativas nacionais fundadoras [...] que leva ao auge da expressão o nacionalismo constitutivo das literaturas desprovidas e emergentes". Ao que tudo indica, ainda não teria saído do Brasil nenhum escritor verdadeiramente autônomo (como Becket), capaz de alterar o tempo literário de Greenwich. Ou seja, parece que do ponto de vista do Brasil, ficamos na mesma, vítimas da língua ou da falta de um escritor verdadeiramente cosmopolita.

6. Finalmente, vale lembrar, como muito acertadamente notou recentemente Graciela Montaldo, que "a postulação do mundo, do mundial, como critério de análise significa estabelecer uma relação de poder assim como o foi a nação para a modernidade" (MONTALDO, 2009, p. 122). Esse esquema, que continua se movimentando sempre do centro para a periferia, vem simplesmente confirmar uma hierarquia que o escritor periférico, e no nosso caso, Nestor Vítor, já percebia muito bem, mas não se contentava simplesmente em denunciar.

Enfim, o que eu gostaria de sugerir aqui é que a releitura desta Paris, escrita por Nestor Vitor, talvez possa servir como uma relativamente modesta, porém incisiva intervenção nos mapas, gráficos, antologias e grandes modelos de circulação internacional, propostos pelo debate em torno da literatura mundial da última década - debate que pelo menos 
nos EUA vem sido representado nas obras da tríade David Damrosh, Franco Moretti e Pascale Casanova, por mais diferentes que sejam suas aproximações. Alguns anos mais tarde, na ocasião do lançamento de um romance de Monteiro Lobato, o escritor demonstra perceber a dinâmica da circulação mundial talvez com maior precisão ainda do que o cenário apresentado por Casanova:

\begin{abstract}
Nova York não pode ainda desbancar Paris no que se chama a hegemonia literária. A França continua a fazer reputações mundiais. Ai, porém, dos proprios fancezes, cujas obras repugnem hoje ao sabor dos "yankees". Do ponto de vista do lucro, entenda-se. A razão principal de estarem tirando uma centena de edições autores de França que ainda são mal conhecidos entre nós, vem do consumo extraordinário que eles têm actualmente nos Estados Unidos. A plethora de ouro em que estes voluptuosamente se debatem e a baixa assustadora do franco até outro dia, crearam tal situação. Os norteamericanos estão absorvendo livros como nunca, tanto mais quanto a lei seca ainda não foi abaixo. Sente-se na propria literatura franceza da vanguarda que alguns dos seus escriptores, e dos considerados de primeira ordem, produzem de olho attento em Tio Sam, embora fingindo pensarem automaticamente em francez.

Monteiro Lobato foi de um processo mais directo: "O Choque das Raças" é pensado e processado em "yankee”, sem disfarce nenhum.

Os norte-americanos atulham-nos os cinemas e os cinemas atulham-nos a cabeça com fitas que nos vão americanisando muito mais rapidamente, sem comparação, do que os seus missionários protestantes. Pois agora que vejam por um livro nosso se não lhes temos aprehendido as lições. Não gastem só nosso café; comprem-nos também romances, tanto mais quando, como $O$ Choque das Raças, eles façam concorrência aos de Welles, de gênio menos inglês que americano. Talvez que por lá, na superabundancia de negocios que os deve estar até embaraçando, muitos dos seus fabuladores tenham deixado de escrever para atirarem-se a empreendimentos ainda mais polpudos, e assim nos permittam inserir um autor nosso entre seus autores de ficção. (VITOR, 1927)
\end{abstract}

\title{
A REPÚBLICA E O MUNDO DAS LETRAS
}

Qual seria então a alternativa apresentada por este viajante brasileiro de ambições cosmopolitas, vindo de uma terra desprovida de museus internacionais, onde quase não há tradição de narrativas de viagem a qual se remeter, gênero este que difere dos museus somente por ser mais banal, espontâneo, e de certo modo mais democrático no aspecto de sua produção - mas que por isso mesmo pode muito facilmente evidenciar o que há de ridículo sobre o autor ou a tradição a qual pertence? E quando o destino e a matéria é Paris, assunto praticamente esgotado por escritores 
de maior talento e prestígio, não será maior ainda o risco do brasileiro sem recursos se expor ao riso do mundo? Mas o que importa para Nestor Vitor é que, em seus sucessivos e inevitáveis contrastes e comparações, este gênero menor, ao ser escrito a partir da América do Sul, talvez possa acresentar muito pouco ao que já se conhece de Paris, mas pode no entanto revelar algo de novo a respeito da "terra em que coube formarmonos," já que o colonizado nunca poderá querer dissimular o "meio de que provimos, pela sua falsa cultura ou sua lastimável estreiteza e deficiência” (VITOR, 1911, p. iii). Além disso, se por um lado, como foi dito, o homem do sul traz em si a indelével marca do colonizador do norte, lembra que a centralidade cosmopolita do norte não deixa de estar colorida, ou mesmo definida por esses visitantes e hóspedes menos célebres, sobre os quais ainda pouco ou quase nada se escreveu; são em grande parte esses, mais ou menos anônimos, que contribuem para "dar variedade à feição dessas velhas civilizações, somos, afinal, uma confirmação a mais do prestígio e da atração que as mesmas exercem sobre o mundo" (VITOR, 1911, p. v). Para Nestor Vitor, ao contrário de Nabuco, o mundo aqui não é apenas o centro que atrai, mas também aquele que por ele é atraído e logo o constitui. Assim, por um lado a narrativa de viagem do homem sul-americano revela sobre Paris o que o francês não quer confessar - ou seja, a natureza colonial do seu próprio cosmopolitismo, "que nos há de apreender quase apenas naquilo que representemos antes de discordante do que de diferente consigo mesmo" - e por outro, revela ao americano do sul aquilo que ele ainda não consegue ver - "modos de ser muito nossos, em estado virtual, porventura, enquanto não deixamos o nosso habitat" (VITOR, 1911, p. vii); e oferece a este uma linguagem para articular aquilo que ele ainda não sabe ou não ousa dizer: "preferimos em muitos casos, conscientemente, ser tido como bárbaro, e tal nos reconhecer, a simular sentimentos, a copiar opiniões que não eram porque não podiam ser nossas" (VITOR, 1911, p. xiv).

Volta a afirmar que a literatura de viagens escrita a partir do sul agrava aquele risco inerente a esse gênero, que já em sua origem dá margens para que o escritor pareça um bocado ridículo; mas que o espaço nacional oferece, em contrapartida, a predisposição de um público leitor que fala a sua língua, um ambiente familiar em que o bárbaro pode ser bárbaro, o ridículo pode ser finalmente ridículo. Sem abdicar do direito de ser universal, mas também se esquivando das grandes rivalidades, ele acolhe este novo provincianismo do meio literário e do público local, assim como as próprias limitações da língua portuguesa, que deixam de ser obstáculos, para serem encarados como um espaço de diálogo ou, digamos, de relativa autonomia: 
Tranquiliza-nos, todavia, uma coisa: a ideia de que ficaremos intramuros, de que falamos exclusivamente para os nossos, resguardados pela nenhuma penetrabilidade do idioma e pela mequinhez dos nossos méritos. Se assim acontecer, ao menos só em casa se aperceberão do espetáculo, e, quando fazemos rir unicamente a familia, compremetemos a nossa repeitabilidade individual tão só. (VITOR, 1911, p. xv)

Assim, acredito antes de mais nada que a obra do escritor paranaense possa, senão subverter, ao menos deslocar um pouco o esquema rígido, bidimensional, proposto pela crítica francesa. Ficamos assim como que tentados a concordar com o escritor, quando este escreve que "o preconceito do povo francês contra a obscuridade impede-o de aprofundar os assuntos, de certo ponto em diante" (VITOR, 1911, p. 399). Vale apontar, por exemplo, a maneira como Casanova termina seu livro, com duas citações de Proust, em que se oferece aos leitores a imagem de uma lente, simbolizando uma nova lógica hermenêutica introduzida pelo seu livro e que, segundo ela, teria o poder de identificar tanto aquilo que está mais distante, assim como o que está mais próximo, "o microscópico e o macroscópico, entre o escritor singular e o vasto mundo literário" (CASANOVA, 2001, p. 421); na segunda citação de Proust, Casanova compara o livro novamente com uma lente de aumento a ser oferecida aos seus leitores para que possam, em exercíco de autoanálise, melhor ver a verdade que estaria dentro deles mesmos, confirmando assim a verdade que o livro apresenta. De fato, muito do que o livro de Pascale Casanova mostra, exibe, descreve, parece difícil de ser negado. Mas o problema está justamente nesta lente que, aumentando, apenas constata, sem no entanto revertar a posição hegemônica dos olhares e dos conhecimentos.

É curioso finalmente notar que esta mesma imagem da lente aparece também no prefácio de Paris, também como metáfora para o livro que se apresenta: "Assim tais objetos lhes ficarão mais perto, de modo a eles terem um pouco a ilusão de os estar vendo, de os estar sentindo, de viver imersos ao seu ambiente. Esse autor americano há de concorrer particularmente feliz para realizar-se, ainda mais do que nunca, a comunhão dos dois mundos, que instintivamente se atraem" (VITOR, 1911, p. ix). Para concluir, diria tão somente que esta visão (ilusória que seja) proposta pela análise de Nestor Vitor, mesmo se ainda presa a um desejo de diálogo entre centro e periferia, possibilita novas conversas entre aqueles que, de volta à casa, se encontram distantes, mas não desligados do Mundo. E, contudo, apesar de suas viagens e suas conversas, o cosmopolita Nestor Vitor permanece ex-cêntrico, excluído mesmo, tanto da república mundial das letras quanto do mundo das letras republicanas. 


\section{4 - Remate de Males 32.1 \\ REFERÊNCIAS BIBLIOGRÁFICAS}

BLANCHOT, Maurice. Le Temps des encyclopédies, La Nouvelle Revue française, 53, (May 1957), pp. 863-74.

BRAGA-PINTO, César. “As Amizades Heteróclitas de Nestor Vítor: Cruz e Sousa e Lima Barreto”. Revista Escritos 4. Rio de Janeiro: Fundação Casa de Rui Barbosa, 2011, pp. 23-6o.

BROCA, Brito. A Vida Literária no Brasil 19oo. Rio de Janeiro: José Olympio Ed., 2004. . Teatro das Letras. Campinas: Unicamp, 1993.

CASANOVA, Pascale. A República Mundial das Letras. Trad. Marina Appenzeller. São Paulo: Estação Liberdade, 2002.

GROSSI, Verónica. "Paris, de Nestor Victor: la construcción textual e imaginaria de una modernidad periférica (la del Brasil de la Belle Époque, 1898-1914)”. In Torre de Papel 3, 1993, pp. 71-84.

GRUZINSKI, Serge. The Mestizo Mind: The Intellectual Dynamics of Colonization and Globalization. Trad. Deke Dusinberre. Nova York e Londres: Routledge, 2002.

KORTE, Barbara. "Chrono-Types: on Forms of Time in the Travelogue". In Writing Travel: The Poetics and Politics of the Modern Journey. Ed. John Zilcolsky. Toronto/ Buffalo/London: U. of Toronto Press, 2008, pp. 26-53.

LINS, Vera. “Os Simbolistas: virando o século”. In O Eixo e a Roda, v. 14, 2007, pp. 113-125.

MICELI, Sergio. Intelectuais à Brasileira. São Paulo: Companhia das Letras, 2001.

MONTALDO, Graciela. “La expulsión de la república, la deserción del mundo”. In Zonas Ciegas: Populismos Y Experimentos Culturales en Argentina. Buenos Aires: Fondo de cultura Económica, 2009. 111-133.

NABUCO, Joaquim. Minha Formação. Fund. Biblioteca Nacional. http://www. dominiopublico.gov.br. Acessado em 11-9-2012.

NITRINI, Sandra. "Viagens reais, viagens literárias: Escritores brasileiros na França”. In Literatura e Sociedade, v. 3, 1998, p. 51-61.

PRENDERGAST, Christopher. "The World Republic of Letters". In Debating World Literature. Ed. Christopher Prendergast. Londres: Verso, 2004, pp. 1-25.

RIERTH, Adolf. Archaeological Fakes. Trans. Diana Imber. New York: Praeger, 1970.

ROMERO, Silvio. Nestor Vitor. História da Literatura Brasileira. tomo V. São Paulo e Rio de Janeiro: Livraria José Olympio, 1949, pp. 388-401. 
SANTIAGO, Silviano. "Atração do Mundo: Políticas de Globalização e de Identidade na Moderna Cultura Brasileira". In O Cosmopolitismo do Pobre. Belo Horizonte: Ed. UFMG, 2004. 11-44.

SERLEN, Rachel. "The Distant Future? Reading Franco Moretti". In Literature Compass, v. 7: 3, 2010, pp. 214-225.

SPIVAK, Gayatri C. An Aesthetic Education in the Era of Globalization. Cambridge, Massachussets: Harvard U. Press, 2012.

VITOR, Nestor. Folhas que ficam: emoções e pensamentos (1900-1914). Rio de Janeiro: Leite Ribeiro \& Maurillo, 1920. . Obra Crítica v. III. Rio de Janeiro: Fundação Casa de Rui Barbosa, 1979. - Paris: Impressões de um Brasileiro. $2^{\underline{a}}$ ed. corrigida. Rio de Janeiro: Livraria Francisco Alves, 1913. . Romances. O Globo, Rio de Janeiro, março de 1927. 